\title{
Proposed minimal diagnostic criteria for myelodysplastic syndromes (MDS) and potential pre-MDS conditions
}

Peter Valent ${ }^{1,2}$, Attilio Orazi ${ }^{3}$, David P. Steensma ${ }^{4}$, Benjamin L. Ebert ${ }^{5}$, Detlef Haase $^{6}$, Luca Malcovati ${ }^{7}$, Arjan A. van de Loosdrecht ${ }^{8}$, Torsten Haferlach ${ }^{9}$, Theresia M. Westers ${ }^{8}$, Denise A. Wells ${ }^{10}$, Aristoteles Giagounidis ${ }^{11}$, Michael Loken ${ }^{10}$, Alberto Orfao $^{12}$, Michael Lübbert ${ }^{13}$, Arnold Ganser ${ }^{14}$, Wolf-Karsten Hofmann ${ }^{15}$, Kiyoyuki Ogata $^{16}$, Julie Schanz ${ }^{6}$, Marie C. Béné ${ }^{17}$, Gregor Hoermann ${ }^{18}$, Wolfgang R. Sperr ${ }^{1,2}$, Karl Sotlar ${ }^{19}$, Peter Bettelheim ${ }^{20}$, Reinhard Stauder ${ }^{21}$, Michael Pfeilstöcker ${ }^{22}$, HansPeter Horny ${ }^{23}$, Ulrich Germing ${ }^{24}$, Peter Greenberg ${ }^{25}$ and John M. Bennett ${ }^{26}$

${ }^{1}$ Department of Internal Medicine I, Division of Hematology \& Hemostaseology, Medical University of Vienna, Vienna, Austria

${ }^{2}$ Ludwig Boltzmann Cluster Oncology, Medical University of Vienna, Vienna, Austria

${ }^{3}$ Department of Pathology and Laboratory Medicine, Weill Cornell Medical College, New York, NY, USA

${ }^{4}$ Division of Hematological Malignancies, Department of Medical Oncology, Dana-Farber Cancer Institute, Harvard Medical School, Boston, MA, USA

${ }^{5}$ Division of Hematology, Department of Medicine, Brigham and Women's Hospital, Harvard Medical School, Boston, MA, USA

${ }^{6}$ Clinic of Hematology and Medical Oncology, Universitymedicine Göttingen, Göttingen, Germany

7 Department of Molecular Medicine, University of Pavia, Pavia, Italy

${ }^{8}$ Department of Hematology Cancer Center Amsterdam, VU University Medical Center, Amsterdam, The Netherlands

${ }^{9}$ Munich Leukemia Laboratory (MLL), Munich, Germany

${ }^{10}$ Hematologics, Inc., Seattle, WA, USA

${ }^{11}$ Department of Internal Medicine II, Marien Hospital, Düsseldorf, Germany

12 Servicio Central de Citometría, Centro de Investigación del Cáncer (IBMCC, CSIC-USAL) and IBSAL, Universidad de Salamanca, Salamanca, Spain

13 Department of Medicine I, Medical Center-University of Freiburg, Freiburg, Germany

14 Department of Hematology, Hemostasis, Oncology, and Stem Cell Transplantation, Hannover Medical School, Hannover, Germany

15 Department of Hematology and Oncology, University Hospital Mannheim, Medical Faculty Mannheim of the University of Heidelberg, Mannheim, Germany

${ }^{16}$ Metropolitan Research and Treatment Center for Blood Disorders (MRTC Japan), Tokyo, Japan

${ }^{17}$ Laboratoire d'Hématologie CHU de Nantes, Nantes, France

18 Department of Laboratory Medicine, Medical University of Vienna, Vienna, Austria

${ }^{19}$ Institute of Pathology, Paracelsus Medical University Salzburg, Salzburg, Austria

${ }^{20}$ Elisabethinen Hospital, Linz, Austria

${ }^{21}$ Department of Internal Medicine V (Haematology and Oncology) Innsbruck Medical University, Innsbruck, Austria

22 3rd Medical Department, Hanusch Hospital, Vienna, Austria

${ }^{23}$ Institute of Pathology, Ludwig-Maximilians University, Munich, Germany

24 Department of Hematology, Oncology, and Clinical Immunology, Heinrich-Heine-University, Düsseldorf, Germany

25 Stanford University Cancer Institute, Stanford, CA, USA

${ }^{26}$ Department of Pathology, Hematopathology Unit and James P Wilmot Cancer Institute, University of Rochester Medical Center, Rochester, New York, USA

Correspondence to: Peter Valent, email: peter.valent@meduniwien.ac.at

Keywords: myelodysplasia, diagnostic criteria, standardization, pre-MDS conditions

Received: May 03, $2017 \quad$ Accepted: June 26, $2017 \quad$ Published: July 05, 2017

Copyright: Valent et al. This is an open-access article distributed under the terms of the Creative Commons Attribution License 3.0 (CC BY 3.0), which permits unrestricted use, distribution, and reproduction in any medium, provided the original author and source are credited. 


\section{ABSTRACT}

Myelodysplastic syndromes (MDS) comprise a heterogeneous group of myeloid neoplasms characterized by peripheral cytopenia, dysplasia, and a variable clinical course with about $30 \%$ risk to transform to secondary acute myeloid leukemia (AML). In the past 15 years, diagnostic evaluations, prognostication, and treatment of MDS have improved substantially. However, with the discovery of molecular markers and advent of novel targeted therapies, new challenges have emerged in the complex field of MDS. For example, MDS-related molecular lesions may be detectable in healthy individuals and increase in prevalence with age. Other patients exhibit persistent cytopenia of unknown etiology without dysplasia. Although these conditions are potential pre-phases of MDS they may also transform into other bone marrow neoplasms. Recently identified molecular, cytogenetic, and flow-based parameters may add in the delineation and prognostication of these conditions. However, no generally accepted integrated classification and no related criteria are as yet available. In an attempt to address this challenge, an international consensus group discussed these issues in a working conference in July 2016. The outcomes of this conference are summarized in the present article which includes criteria and a proposal for the classification of pre-MDS conditions as well as updated minimal diagnostic criteria of MDS. Moreover, we propose diagnostic standards to delineate between 'normal", pre-MDS, and MDS. These standards and criteria should facilitate diagnostic and prognostic evaluations in clinical studies as well as in clinical practice.

\section{INTRODUCTION}

Myelodysplastic syndromes (MDS) comprise a heterogeneous group of myeloid neoplasms defined by peripheral cytopenia, bone marrow (BM) failure, morphologic dysplasia in one or more hematopoietic lineages, and genetic instability with increased risk to transform to secondary acute myeloid leukemia (AML) [14]. Morphologic dysplasia represents a major diagnostic criterion of MDS and can be detected in erythroid cells, neutrophilic cells and megakaryocytes. However, it is often difficult to define the degree of dysplasia and there is always a certain inter-observer variability when dysplastic cells are counted on BM smears.

A first classification of the MDS was introduced by the French-American-British (FAB) cooperative working group $[5,6]$. This proposal was based on cytomorphologic criteria and served as standard for many years. Between 2001 and 2016, the World Health Organization (WHO) created updated versions of this proposal [7-9]. However, within WHO categories of MDS, the course and prognosis vary significantly among patients, depending on age, comorbidities, karyotype, somatic mutations, and epigenetic features of the dominant clones [1-4, 10-12]. In addition, most cytogenetic and molecular markers, although being useful in the diagnosis and prognostication of MDS, are not specific for MDS, but are also found in other BM neoplasms. Moreover, many mutations identified in patients with MDS may also be detected in healthy elderly individuals [13-15]. Other patients have persistent cytopenia of unknown etiology without morphologic or cytogenetic evidence of MDS or other underlying pathologies, a condition termed idiopathic cytopenia of undetermined significance (ICUS) [16-19].

Although all these conditions are potential prephases of MDS, they may also develop into other hematopoietic neoplasms or may just persist without clinical manifestations [13-19]. It is therefore important to develop prognostic parameters (predicting MDS evolution) and to define these conditions using solid criteria and a generally accepted (suitable) nomenclature. Several of the recently discovered cytogenetic, molecular, and flow cytometry-based markers may help in the delineation and prognostication of these conditions. However, although preliminary proposals for the definition and classification of some pre-MDS conditions have been published [15-17] no generally accepted criteria or classification are as yet available.

In 2006, an international working group made a first attempt to address the issue of potential pre-MDS conditions [16]. In an effort to refine these definitions and to discuss the biology, terminologies, and criteria of preMDS conditions, these experts met again in Vienna in a working conference in 2016 (July 1-3). The outcomes of this conference are summarized here and include proposed criteria for a classification of pre-MDS conditions as well as a proposed update for minimal diagnostic criteria of MDS. In addition, new diagnostic standards are discussed. Details about the conference and the consensus discussion are described in the supplement. 


\section{DEFINITION OF MDS AND MINIMAL DIAGNOSTIC CRITERIA}

MDS are characterized by peripheral cytopenia, BM failure, morphologic dysplasia in one or more myeloid lineages, and genetic instability with increased risk to transform to AML. The term 'syndrome' indicates clinical relevance and thus implies that cytopenia is an important diagnostic feature. In most patients, a straightforward diagnosis of MDS can be made on the basis of WHO criteria [7-9]. However, in some patients with cytopenia, it may be difficult to establish or exclude overt MDS. These are patients without cytogenetic anomalies and/or only mild cytopenia, patients with an abnormal karyotype and mild cytopenia but no overt dysplasia, or patients with transfusion-dependent macrocytic anemia without karyotypic anomalies, molecular markers, or diagnostic dysplasia. To assist in these cases, minimal diagnostic criteria have been proposed by the WHO in 2001 and 2008 $[7,8]$ and by our working group in 2007 [16]. Our group is of the opinion that these criteria are still valid but need slight adjustments, based on novel markers and improved diagnostic approaches. Proposed revised (updated) minimal diagnostic criteria sufficient to establish the diagnosis of 'MDS' are presented in Table 1. MDS are characterized by BM failure with peripheral cytopenia and cyto-morphologic dysplasia in erythroid cells and/or neutrophils and/or megakaryocytes. Prerequisite criteria, which must be fulfilled, include i) persistent cytopenia for at least 4 months (unless a blast cell excess and MDSrelated cytogenetic abnormalities are present: in these patients the diagnosis can be established without delay) and ii) exclusion that another underlying condition serves as a primary cause (trigger) of cytopenia and/or dysplasia. The degree of cytopenia that qualifies as a criterion of MDS has been a matter of debate [16, 20-22]. Analyses of studies including the MDS databases which generated the international prognostic scoring system (IPSS) and its revision, the IPSS-R, have demonstrated that use of standard hematologic values to define cytopenic cutoffs for MDS diagnosis may be more appropriate than the WHO-recommended thresholds, also being cognizant of conditional (age-, altitude-, sex-, and ethnic-related) blood count variations [22]. Thus, our faculty is of the opinion that standard hematologic values should be employed to define cytopenia levels needed for the diagnosis of MDS. In the absence of cytopenia (defined by local institutional ranges), however, MDS should not be diagnosed. In these patients, a pre-MDS condition may be identified.

Major (MDS-related) criteria include i) dysplasia of at least $10 \%$ of cells in one or more major BM lineage(s) (erythroid, neutrophilic, megakaryocytic) or an increase in ring sideroblasts (RS) of $\geq 15 \%$ (or $\geq 5 \%$ in the presence of a $S F 3 B 1$ mutation), ii) an increase in myeloblasts of 5-19\% in dysplastic BM smears (in the absence of AML-specific gene rearrangements) or 2-19\% myeloblasts in peripheral blood smears, and iii) a MDS-related (5q-, -7, complex, etc.) karyotype (Table 1). At least one of these major MDS criteria has to be met (together with pre-requisite-criteria) to arrive at the diagnosis of MDS. When MDS-related (major) criteria are not fulfilled but the patient exhibits typical clinical features (e.g. macrocytic transfusiondependent anemia) and no other underlying disease can be detected, the diagnosis of MDS can still be considered (can be provisionally proposed) when certain MDS co-criteria are met. These co-criteria include typical histologic and immunohistochemical findings, typical multi-parameter flow cytometry (MFC) patterns, and typical somatic mutations (Table 1). The minimal allele burden required to count as a co-criterion of MDS remains uncertain. Whereas a minimum burden of $2 \%$ was used as a working definition of clonal hematopoiesis with indeterminate potential (CHIP) [15], the allele burden is usually higher in MDS (often $>10 \%$ ) (Table 1). The presence of multiple mutations (typically seen in MDS, e.g. $S F 3 B 1$ ) increases the likelihood that the patient suffers from a myeloid neoplasm resembling MDS or will develop MDS during follow up. An impaired BM function, as demonstrated by a reduced number of colony-forming progenitor cells (CFU), was also proposed as co-criterion of MDS in our initial proposal [16]. However, in most centers, the CFU assay is not performed routinely. Therefore, this cocriterion, although helpful, was removed in our updated proposal. BM histology and immunohistochemistry results (e.g. megakaryocyte dysplasia or a blast cell increase) may also support the diagnosis of MDS [23-25]. Therefore, a definitive conclusion by the hematopathologist that BM histology- and/or immunostaining results are consistent with MDS are now also included as a co-criterion (Table 1). When all evaluations are negative and the patient is classified as ICUS, the recommended standard is to follow the clinical course and to perform laboratory blood parameters regularly. A repeat BM examination is recommended depending on laboratory findings and the clinical course (as in low risk MDS patients) [16].

\section{POTENTIAL PRE-PHASES OF MDS}

During the past decade, several interface- and potential pre-MDS conditions have been proposed, including ICUS, idiopathic dysplasia of unknown significance (IDUS), clonal cytopenia of unknown significance (CCUS) and CHIP [15-19]. It is important to note that these conditions may i) persist without clinical manifestations, ii) progress to MDS after a variable time period, iii) progress to another myeloid neoplasm, or iv) progress to another hematologic or even non-hematologic disease. Therefore, the appendices 'US' (for undetermined/ unknown significance) or IP (indeterminate potential) are appropriate in these definitions. Table 2 shows a summary of these conditions, together with specific features and proposed defining criteria. In the following paragraphs, 
Table 1: Proposed minimal diagnostic criteria of MDS*

A. Prerequisite Criteria (both must be fulfilled)

- Persistent (4 months) peripheral blood cytopenia** in one or more of the following lineages: erythroid cells, neutrophils, platelets (exception: in the presence of a blast cell excess and MDS-related cytogenetic abnormalities the diagnosis of MDS can be established without delay)

- Exclusion of all other hematopoietic or non-hematopoietic disorders as primary reason for cytopenia/dysplasia***

B. MDS-Related (Major) Criteria (at least one must be fulfilled)

- Dysplasia in at least $10 \%$ of all cells in one of the following lineages in the bone marrow smear: erythroid; neutrophilic; megakaryocytic****

$-\geq 15 \%$ ring sideroblasts (iron stain) or $\geq 5 \%$ ring sideroblasts (iron stain) in the presence of $S F 3 B 1$ mutation

- 5-19\% myeloblasts on bone marrow smears (or 2-19\% myeloblasts on blood smears)

- Typical chromosome abnormality(ies) by conventional karyotyping or $\mathrm{FISH}^{* * * * *}$

C. Co-Criteria (for patients fulfilling A but not B, and otherwise show typical clinical features, e.g. macrocytic transfusion-dependent anemia; two or more of these co-criteria must be fulfilled for considering a provisional diagnosis of MDS)

- Abnormal findings in histologic and/or immunohistochemical studies of bone marrow biopsy sections supporting the diagnosis of MDS****

- Abnormal immunophenotype of bone marrow cells by flow cytometry, with multiple MDS-associated phenotypic aberrancies indicating the presence of a monoclonal population of erythroid and/or myeloid cells

- Evidence of a clonal population of myeloid cells determined by molecular (sequencing) studies revealing MDS-related mutations*******

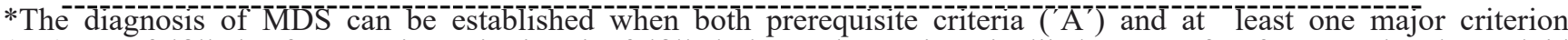
('B') are fulfilled. If no major criterion is fulfilled, but the patient is likely to suffer from a clonal myeloid disease, co-criteria ('C') should be applied and may help in reaching the conclusion that the patient has a myloid neoplasm resembling MDS or will develop MDS. In this diagnostic setting, repeated bone marrow investigations during follow-up may be required to arrive at a final diagnosis of MDS.

**Cytopenia defined by local institutional reference values.

***As more and more patients with two co-existing bone marrow neoplasms are diagnosed, it is important to state that in rare cases, MDS can be diagnosed even if another co-existing disease potentially causing cytopenia is also detected.

****Examples: clusters of abnormally localized immature precursors (ALIP); clusters of CD34+ blast cells; dysplastic micromegakaryocytes detected by immunohistochemistry ( $\geq 10 \%$ dysplastic megakaryocytes).

*****Typical chromosome abnormalities are those recurrently and typically found in MDS patients (e.g. 5q-, -7) and considered as indicative of MDS by the WHO even in the absence of morphologic criteria of MDS.

$* * * * * *$ Detection of multiple mutations typically seen in MDS (e.g. SF3B1) increases the likelihood that the patient suffers from MDS or will develop MDS.

Abbreviations: MDS, myelodysplastic syndrome(s); FISH, fluorescence in situ hybridization; WHO, World Health Organization; Hb, hemoglobin; ANC, absolute neutrophil count. 
Table 2: Pre-MDS and MDS conditions: typical features and criteria

\begin{tabular}{|c|c|c|c|c|c|c|}
\hline \multirow[b]{2}{*}{ Feature } & \multicolumn{6}{|c|}{ Pre-MDS Conditions and MDS } \\
\hline & ICUS & IDUS & CHIP & CCUS & LR MDS & HR MDS \\
\hline Monoclonal/ & & & & & & \\
\hline Oligoclonal & $-/+$ & $+/-$ & + & + & + & + \\
\hline Dysplasia* & - & + & - & - & + & + \\
\hline Cytopenia(s)** & + & - & - & + & + & + \\
\hline BM blasts & $<5 \%$ & $<5 \%$ & $<5 \%$ & $<5 \%$ & $<5 \%$ & $<20 \%$ \\
\hline Flow abnormalities & $+/-$ & $+/-$ & $+/-$ & $+/-$ & ++ & +++ \\
\hline $\begin{array}{l}\text { Cytogenetic } \\
\text { abnormalities }\end{array}$ & $-/+* * *$ & $-/+* * *$ & $+/-$ & - & + & ++ \\
\hline $\begin{array}{l}\text { Molecular } \\
\text { aberration/s**** }\end{array}$ & - & - & + & + & ++ & +++ \\
\hline
\end{tabular}

*At least $10 \%$ of all cells in a given lineage (erythroid, neutrophil, or megakaryocyte) are dysplastic.

**Persistent cytopenia(s) recorded over a time-period of at least 4 months.

***In a subset of cases, a small-sized clone with MDS-related anomaly is detectable by FISH.

$* * * *$ A molecular aberration is defined by MDS-related mutations and an allele burden of $\geq 2 \%$. The working definition for pre-MDS conditions is also $\geq 2 \%$ allele burden, whereas the minimal allele burden to count as a co-criterion of MDS should be higher (e.g. 10\%). However, a high allele burden does not exclude the presence of CHIP or CCUS. It is also important to note that in most patients with MDS, multiple gene mutations/aberrations are found. When several co-criteria of MDS are present, the diagnosis MDS can be established in the absence of diagnostic dysplasia.

Abbreviations: MDS, myelodysplastic syndrome(s); ICUS, idiopathic cytopenia of undetermined significance; IDUS, idiopathic dysplasia of undetermined significance; CCUS, clonal cytopenia of undetermined significance; LR, low risk; HR, high risk; BM bone marrow, FISH, fluorescence in situ hybridization.

their features and clinical impact are reviewed.

\section{Idiopathic cytopenia of undetermined (unknown) significance (ICUS)}

ICUS is defined by cytopenia of any degree in one or more lineages: erythrocytes, neutrophils, or platelets. The cytopenia has to be i) persistent ( $\geq 4$ months), ii) lacking minimal diagnostic criteria of MDS and iii) not explained by any other hematologic or non-hematologic disease (Supplementary Table S1) [16, 19]. In some ICUS patients, the type of cytopenia (e.g. transfusion-dependent macrocytic anemia) may point to the potential of MDS or a MDS-prephase. Patients with ICUS are further subdivided into ICUS-A (anemia), ICUS-N (neutropenia), ICUS-T (thrombocytopenia), and ICUS-PAN (bi/ pancytopenia) (Supplementary Table S2) [19]. The precise clinical implication of this classification remains to be determined. Apart from MDS, differential diagnoses to ICUS-N include, among others, drug-induced neutropenia, chronic hepathopathies, autoimmune disorders, and cyclic neutropenia. ICUS-T has to be separated from immunemediated thrombocytopenia (ITP) where platelets are usually dropping quickly to very low levels, whereas this is not the case in ICUS-T. In patients without a clear diagnosis but otherwise suggestive (MDS-related) features, further tests and markers should be applied to confirm or exclude BM failure and the presence of a clonal cell population (e.g. by fluorescence in situ hybridization [FISH], MFC, and molecular analyses). Depending on the specific clinical situation and laboratory features, specific molecular tests and markers (example: JAK2 V617F in the case of BM fibrosis) should be applied [16, 19, 25]. The clinical course in patients with ICUS is variable. Some of these patients will progress to MDS or AML [16-19, 26]. Other patients may develop a lymphoproliferative 
Table 3: Causes of bone marrow (BM) cell dysplasia and cytopenia

\begin{tabular}{|c|c|}
\hline Cause / Etiology & Marker / Diagnostics* \\
\hline Inherited bone marrow failure syndromes & Family history and genetic tests \\
\hline Myeloid neoplasms affecting the BM** & Hematologic diagnosis (WHO criteria) \\
\hline Lymphoproliferative neoplasms (T-LGL) & Hematologic diagnosis (WHO criteria) \\
\hline Paroxysmal nocturnal hemoglobinuria (PNH) & PI-linked antigens (PIG-A mutation) \\
\hline Pure red cell aplasia (PRCA) & Reticulocyte count - dynamics \\
\hline $\begin{array}{l}\text { Gelatinous BM transformation } \\
\text { (=serous atrophy of bone marrow) }\end{array}$ & Case history, BM histology \\
\hline Vitamin B12 or folate deficiency & Serum vitamin measurements \\
\hline Copper deficiency & Case history, serum copper measurement \\
\hline $\begin{array}{l}\text { Viral infections (CMV, EBV, HIV, } \\
\text { parvo virus B19, hepatitis, others) }\end{array}$ & Virology \\
\hline Bacterial infections & Bacteriology \\
\hline Visceral leishmaniasis & Parasitology and cytology \\
\hline Autoimmune disorders & Immunology diagnostic algorithms \\
\hline Other chronic inflammatory processes & Inflammation-related parameters \\
\hline Chronic kidney failure & Nephrology diagnostic algorithms \\
\hline Chronic liver diseases*** & Hepatology diagnostic algorithms \\
\hline Drug-induced BM reactions & Drug intake - case history \\
\hline Chemotherapy & Oncologic case history \\
\hline BM stem cell transplantation & - \\
\hline Radiation damage & Measurements to estimate radiation exposure \\
\hline Toxic damage (various toxins) & Toxicology \\
\hline
\end{tabular}

*For all differential diagnoses, a detailed investigation of the BM by cytology, histology, immunohistochemistry (and where relevant flow cytometry), is required.

**Apart from MDS, most other myeloid neoplasms affecting the BM can also produce mild or even marked BM cell dysplasia. In many cases, long-term therapy with cytoreductive agents promotes the dysplasia.

***Chronic liver diseases, such as chronic hepatitis or alcohol-induced hepathopathies leading to liver cirrhosis, are typically associated with neutropenia and thrombocytopenia.

Abbreviations: BM, bone marrow; T-LGL, T cell large granular lymphocyte leukemia; CMV, cytomegaly virus; EBV, Epstein Barr virus; HIV, human immunodeficiency virus.

neoplasm or mast cell neoplasm. In some patients, a small-sized clone is initially detected by FISH, MFC, or molecular analyses [18, 27-29]. These patients may have a higher risk to transform into MDS or another BM neoplasm. As soon as MDS-related molecular aberrations are detected in a patient with ICUS, the diagnosis may change to CCUS (mutation with $\geq 2 \%$ allele burden and no other signs or co-criteria of MDS present) or MDS (other MDS criteria also present) (Table 2).

\section{Idiopathic dysplasia of undetermined (unknown) significance (IDUS)}

More and more patients are referred with no, slight, or only transient cytopenia, but peripheral blood (PB) abnormalities resembling dysplasia (band cells, Pseudo Pelger forms, hypogranulated neutrophils, unexplained macrocytosis). In several of these cases, BM examinations show mild to marked signs of dysplasia in one or more lineages $[17,19,30]$. In the absence of any detectable cytopenia and absence of any cytogenetic or molecular abnormalities, this condition should be called IDUS. In 
Table 4: Value and impact of BM histology and immunohistochemistry (IHC) in MDS

Diagnosis of hypocellular (hypoplastic) MDS

Diagnosis of MDS-U

Separation from AML when smears are of poor

quality or blood-contaminated

Separation from hypoplastic AML

Separation from aplastic anemia

Separation from lymphoproliferative disorders

Diagnosis of a concomitant (underlying) mastocytosis

Multifocal accumulations of progenitor cells

Abnormal distribution/localization of progenitor cells**

Abnormal accumulation and morphology

(dysplasia) of megakaryocytes***

Demonstration of bone marrow fibrosis

Demonstration of increased angiogenesis
Cellularity, CD34

CD34 (CD117/KIT*)

CD34 (CD117/KIT*), cellularity

Cellularity, CD34

T cell / B cell markers

KIT, tryptase

CD34

CD34 (CD117/KIT*)

$\mathrm{CD} 42 b, \mathrm{CD} 61, \mathrm{CD} 31$

Gömöri's silver impregnation

CD31, CD34

*An increase in CD34+ cells by IHC can assist in the quantification of the progenitor (blast) cell compartment in MDS. In the case that BM blast cells lack expression of CD34, CD117/KIT should be employed as an alternative stain for the visualization and enumeration of immature precursor cells.

**The previously used term 'atypical localization of immature precursor cells (ALIP)' is obsolete and should no longer be used.

***In many patients with MDS, demonstration of megakaryocyte dysplasia is only possible by a histologic and immunohistochemical investigation of the BM. Note that immature megakaryocytes (megakaryoblasts) may only be detectable by IHC.

Abbreviations: BM, bone marrow; AML, acute myeloid leukemia; IHC, immunohistochemistry; MDS-U, unclassifiable MDS.

fact, a number of reactive conditions and other pathologies can provoke mild or even marked dysplasia in normal (polyclonal) BM cells, with or without cytopenia, and in several of these cases, a reactive non-hematopoietic disease or a deficiency syndrome (e.g. copper deficiency) may be identified during follow-up (Table 3). Therefore, the term IDUS seems justified. However, as soon as persistent cytopenia and other MDS-related criteria are also detected, the diagnosis changes to MDS. The definition of IDUS is shown in Supplementary Table S3.

\section{Clonal hematopoiesis of indeterminate potential (CHIP)}

Since cancer is generally caused by the serial acquisition of multiple mutations, the appearance of an initial somatic mutation in a gene that drives myeloid malignancies in a healthy hematopoietic stem cell may lead to clonal expansion in the absence of overt malignancy $[31,32]$. In fact, hematopoietic (stem) cells can acquire somatic lesions (mutations) during the lifetime of a healthy individual, the vast majority of which confer a neutral or negative effect on the survival and expansion of the stem cell, without definitive signs of a BM neoplasm [13-15]. As a result, somatic mutations that are otherwise typically found in MDS or other BM neoplasms, are detected in a subset of healthy individuals, and the prevalence of such clones increases with age [13-15, 33]. The term CHIP was created to define the state in which a somatic genetic alteration in a gene that is recurrently mutated in hematologic malignancies is identified in an otherwise healthy individual [15]. Although initially discussed in the context of MDS, CHIP must be regarded as a more general phenomenon. In particular, individuals with CHIP have an increased risk of acquiring a hematologic malignancy, and may progress to MDS, but may also develop other myeloid or even lymphoid neoplasms. It has also been shown that CHIP is associated with an increased risk to develop therapy-related myeloid neoplasms [34-36]. However, not all patients with CHIP develop an overt malignancy during their lifetime.

With regard to the minimal clone size, a first proposal was that the mutant allele burden in the PB should be $\geq 2 \%$ to call a condition CHIP [15]. Our group is of the opinion that this proposal should qualify as a general working definition of CHIP, provided that the other criteria of CHIP are also fulfilled. The full 
Table 5: Somatically mutated genes detectable in patients with MDS and CHIP

\begin{tabular}{|c|c|c|c|c|}
\hline \multirow{2}{*}{$\begin{array}{l}\text { Gene } \\
\text { Abbreviation }\end{array}$} & \multirow{2}{*}{$\begin{array}{l}\text { Gene } \\
\text { Name }\end{array}$} & \multirow{2}{*}{$\begin{array}{c}\text { Chromosome } \\
\text { Location }\end{array}$} & \multicolumn{2}{|c|}{ Frequency* } \\
\hline & & & MDS & CHIP \\
\hline$N R A S$ & Neuroblastoma RAS oncogene & $1 \mathrm{p} 13.2$ & $+/-$ & - \\
\hline DNMT3A & DNA-methyltransferase 3 alpha & 2 p23 & + & + \\
\hline$S F 3 B 1$ & Splicing factor $3 \mathrm{~b}$, subunit 1 & $2 \mathrm{q} 33.1$ & + & $+/-$ \\
\hline IDH1 & Isocitrate dehydrogenase 1 & $2 q 33.3$ & $+/-$ & - \\
\hline GATA2 & GATA binding protein 2 & $3 \mathrm{q} 21.3$ & - & - \\
\hline KIT & V-kit oncogene homolog & $4 q 11-12$ & $+/-$ & - \\
\hline TET2 & Tet methylcytosine deoxygenase 2 & $4 \mathrm{q} 24$ & + & + \\
\hline NPMI & Nucleophosmin & $5 \mathrm{q} 35.1$ & - & - \\
\hline EZH2 & Enhancer of zeste homolog 2 & $7 q 35-36$ & $+/-$ & - \\
\hline JAK2 & Janus Kinase 2 & 9 p24 & $+/-$ & + \\
\hline$C B L$ & CBL proto-oncogene & $11 \mathrm{q} 23.3$ & $+/-$ & $+/-$ \\
\hline$K R A S$ & Kirsten sarcoma viral oncogene & $12 \mathrm{p} 12-11$ & - & - \\
\hline ETV6 & Ets variant 6 & $12 \mathrm{p} 13$ & - & - \\
\hline FLT3 & Fms-related tyrosine kinase 3 & $13 q 12$ & - & - \\
\hline $\mathrm{IDH} 2$ & Isocitrate dehydrogenase 2 & $15 q 26.1$ & - & - \\
\hline TP53 & Tumor protein $\mathrm{p} 53$ & $17 \mathrm{p} 13.1$ & $+/-$ & $+/-$ \\
\hline PRPF8 & Pre-mRNA processing factor 8 & $17 \mathrm{p} 13.3$ & - & - \\
\hline$S R S F 2$ & Serine/arginine-rich splicing factor 2 & $17 \mathrm{q} 25.1$ & + & $+/-$ \\
\hline CEBPA & CCAAT/enhancer-binding protein A & $19 \mathrm{q} 13.1$ & - & - \\
\hline$A S X L 1$ & Additional sex combs like 1 & 20q11 & + & + \\
\hline$U 2 A F 1$ & U2s nuclear RNA auxiliary factor 1 & $21 \mathrm{q} 22.3$ & $+/-$ & - \\
\hline RUNX1 & Runt-related transcription factor 1 & $21 \mathrm{q} 22.12$ & $+/-$ & - \\
\hline BCOR & BCL6 Corepressor & Xp11.4 & - & - \\
\hline ZRSR2 & Zinc finger (CCCG type) & Xp22.1 & $+/-$ & - \\
\hline STAG2 & Cohesin complex factor & $\mathrm{Xq} 25$ & $+/-$ & - \\
\hline
\end{tabular}

Gene names refer to standard nomenclature. MDS, myelodysplastic syndromes; CHIP, clonal hematopoiesis of indeterminate potential.

*Score of frequency:,$-<1 \% ;+/-, 1-10 \% ;+,>10 \%$ of all patients.

The presence of multiple mutations typically seen in MDS (e.g. SF3B1, SRSF2) increases the likelihood that the patient suffers from MDS or will develop MDS.

definition of CHIP includes the absence of persistent $(\geq$ 4 months) cytopenia and exclusion of other underlying conditions as primary reason for the observed mutation(s) in a non-cytopenic patient (Table 2, Supplementary Table S4). For example, the preliminary diagnosis of CHIP would change into systemic mastocytosis as soon as mastocytosis is detected in a BM biopsy (even if no cytopenia is present). An unresolved question is whether evidence of clonal expansion of any type of hematopoietic cells should qualify as 'indicative of CHIP'. Individuals with CHIP who have the potential to develop MDS will likely have mutations that are known to be recurrently mutated in MDS [15]. It is not yet clear whether some of these MDS-related mutations have a higher prognostic impact than others with regard to progression to MDS or overall survival [37]. Therefore, we are of the opinion that CHIP should (for the moment) not be sub-classified into prognostically different groups (or terms). Finally, the term CHIP should only be used for individuals who have a normal blood count.

\section{Clonal cytopenia of unknown significance (CCUS)}

The term CCUS has been suggested for patients in whom cytopenia and clonal abnormalities are found, but no dysplasia is seen and no other clonal BM neoplasm is detected (Table 2) [15]. Our group is of the opinion that 
Table 6: Recurrent immunophenotypic abnormalities detected by flow cytometry in MDS

$\mathrm{CD} 34^{+}$progenitor cells

- increase in $\mathrm{CD}_{3} 4^{+}$cells*

- absolute and relative (to all $\mathrm{CD} 34^{+}$) decrease in number of

$\mathrm{CD} 34^{+} / \mathrm{CD} 10^{+}$or $\mathrm{CD} 34^{+} / \mathrm{CD} 19^{+}$cells (hematogones)

- abnormal expression of CD45, CD34 or CD117

- abnormal granularity (sideward light scatter)

- overexpression or lack of expression of CD13, CD33, or HLA-DR

- expression of 'lymphoid' antigens: CD5, CD7, CD19, or CD56

- expression of CD11b and/or overexpression of CD15

Maturing Neutrophils

- decreased granularity (sideward light scatter)

- abnormal distribution of immature and mature subsets

- lack of or abnormal expression of CD11b, CD13 or CD33

- delayed expression of CD16 or lack of CD10

- expression of CD56

\section{Monocytes}

- lack of or abnormal expression of CD13, CD14, CD16, or CD33

- abnormal expression of CD11b or HLA-DR

- overexpression of CD56

- abnormal granularity or distribution of immature and mature subsets

Erythroid precursor cells

- decreased or heterogeneous expression of CD36 and CD71

- abnormal frequency of $\mathrm{CD} 117^{+}$erythroid precursors

- abnormal frequency of $\mathrm{CD} 105^{+}$erythroid precursors

- abnormal CD105 fluorescence intensity

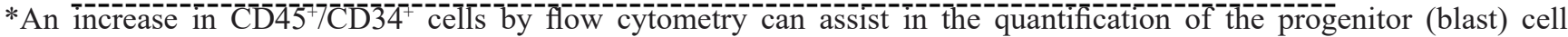
compartment in MDS. In cases where blast cells lack CD34, CD117/KIT can be employed as alternative marker of progenitor (blast) cells. MDS, myelodysplastic syndromes

CCUS should only apply when all investigations have excluded MDS, i.e. no MDS-related morphologic or MFC abnormalities and no MDS-related cytogenetic lesions (like 5q-) are found. In other words, in the presence of either MDS-related criteria or definitive (multiple) cocriteria, the diagnosis CCUS may change to MDS. Likewise, in a patient with cytopenia and typical MFC pattern or typical immunohistochemical findings (e.g. megakaryocyte dysplasia), a provisional diagnosis of MDS may be established even if the clonal marker is not specific for MDS (example: TET2 mutation with high allele burden). The term CCUS should thus be reserved for rare conditions where no or only slight $(<10 \%) \mathrm{BM}$ dysplasia and no definitive cytogenetic, histologic or MFC-based signs of MDS are detected (Supplementary
Table S5). With regard to the allelic burden, the same working definition should apply as for CHIP ( $\geq 2 \%$ ). In the presence of multiple mutations, the likelihood that the patient has or will develop MDS is higher. Another important differential diagnosis to consider is a myeloid neoplasm with germline predisposition, a new entity recently proposed by the WHO.

\section{THE BM AND PB SMEAR: STANDARDS AND RECOMMENDATIONS}

The examination of representative and appropriately prepared and stained BM and PB smears remains an essential diagnostic approach in suspected MDS [4-8, 16, 38-42]. For proper morphologic assessment, well- 
prepared thin films from sufficient material and an appropriate stain (e.g. Pappenheim, Romanowsky, or Wright-Giemsa) are required [16]. At least 500 nucleated cells should be counted in the BM smear. In each case, BM cellularity, the erythroid-to-myeloid (E:M) ratio, and the percentage of blast cells should be recorded [9, 16, 39]. When at least $10 \%$ of cells in the erythroid, neutrophil, or megakaryocyte lineage(s) are dysplastic, the diagnosis of MDS can be established provided that cytopenia is present and other diseases have been excluded as reason for dysplasia and cytopenia. An iron stain (with Perls' reagent) should be performed in all cases in order to identify and count RS. Because 5\% is the lower cut-off limit to diagnose cytopenia with RS in the presence of an SF3B1 mutation (MDS-RS) [9, 41], a minimal number of 100 nucleated red cells should be examined. In the absence of an SF3B1 mutation, the demonstration of $\geq$ $15 \% \mathrm{RS}$ is indicative of erythroid dysplasia and supports the diagnosis of MDS-RS. In both instances, the diagnosis MDS can be established in a cytopenic patient ( $\mathrm{RS}+$ ) even if morphologic dysplasia is only seen in $<10 \%$ of cells in the three major BM lineages.

Guidelines for the detection, classification, and enumeration of blast cells and RS in the BM smear in MDS have been published recently [38-40]. Megakaryocytes often display signs of morphologic dysplasia in MDS. However, even in well-prepared BM smears, the number of megakaryocytes may be too low to define a percentage of dysplastic cells. Therefore, megakaryocytic dysplasia is often defined histologically in BM biopsy sections. Monocytes may be increased in number in BM smears and may be quite immature. If monocytes are particularly immature, it may be difficult to discriminate them from blast cells by morphology. Erythroid cells and their progenitors usually show dysplasia in MDS, which should be reported in qualitative terms (mild, moderate, severe) and quantitatively as percent count. Blast cells should be counted as percent of all nucleated BM cells independent of erythroid predominance. In other words, many cases formerly diagnosed as AML FAB M6 based on erythroid predominance (where blast cells were counted as percentage of all nucleated BM cells after subtraction of erythroid cells) are now classified as MDS, based on the lower blast count in the total BM cell compartment $[9,41,43]$. It is also important to examine well-prepared and appropriately stained PB smears in all cases with suspected or known MDS and to report morphologic features (e.g. absence of granulation) and the percentages of various cell types, including Pseudo-Pelger forms, hypogranulated neutrophils, blast cells, and monocytic cells [16]. The number of reticulocytes should also be determined in all patients with suspected or known MDS.

\section{BONE MARROW HISTOLOGY AND IMMUNOHISTOCHEMISTRY (IHC): CURRENT STANDARDS}

In all patients with suspected MDS, a thorough investigation of appropriately processed and stained BM biopsy sections by histology and IHC should be performed [16, 23-25]. In (suspected) pre-MDS conditions, histologic investigation is required to exclude an overt BM neoplasm and other disorders, such as gelatinous transformation, infection, or BM carcinosis. In patients with established MDS, BM histology and IHC provide important diagnostic information and/or may reveal prognostic features, including BM fibrosis, a focal increase in CD34+ progenitors, increased angiogenesis, a hypocellular BM or concomitant mastocytosis (Table 4) [23-25]. The evaluation and enumeration of $\mathrm{CD}^{+} 4^{+}$progenitor cells and $\mathrm{CD} 117 / \mathrm{KIT}^{+}$cells by $\mathrm{IHC}$ in BM biopsy sections is important and can confirm morphologic results in uncertain cases where e.g. BM smears were contaminated with PB [16, 23-25].

BM biopsy specimens are usually taken from the posterior iliac spine and should be of adequate length $(\geq$ $1.5 \mathrm{~cm})[16,25]$. The specimen should be fixed in neutral formalin (or alternative standard fixation), decalcified in EDTA (at least 8 hours), and embedded in paraffin-wax $[16,25]$. Ideally $1 \mu \mathrm{m}$-thin sections should be performed, however, up to $3 \mu \mathrm{m}$ is acceptable. Standard routine stains include hematoxylin-eosin (H\&E), Giemsa, Prussian blue, AS-D chloroacetate esterase (CAE), and Gömöri's silver impregnation. CAE is of value for the detection of minor alterations of the microarchitecture of the $\mathrm{BM}$, including minute infiltrates of CAE-negative cells (e.g. myeloblasts) [23]. Cellularity of the BM should be reported according to published proposals $[44,45]$. For routine purposes, it is recommended that the pathologist determines the cellularity as 'normocellular', 'hypocellular', or 'hypercellular', based on an age-adapted estimate [46].

The application of IHC is recommended in all patients with (suspected) MDS [16, 23-25]. The minimal IHC-panel should include CD34 (stem/progenitor cells), CD117/KIT (progenitor cells and mast cells), a megakaryocyte marker (like CD42b or CD61), and tryptase (mast cells, immature basophils) (Supplementary Table S6) [16, 25]. In difficult cases, additional lineagespecific antibodies such as CD3, CD14, or CD20, should be applied, depending on the differential diagnoses (Table 3). When employing CD34 as a progenitor-related IHC marker in MDS, it is important to know that endothelial cells also express this antigen. Another important point is that, in some patients with MDS, progenitor cells may be CD34-negative. In such cases, KIT/CD117 should be applied as alternative marker (Table 4). Nevertheless, in most cases, a straightforward approach is to stain and count progenitor cells (blasts) using antibodies against CD34 [23, 25, 47, 48]. Megakaryocyte markers enable 
the enumeration of immature and mature megakaryocytes as well as detection of atypical accumulations (grouping, clustering) and cytomorphological dysplasia of these cells $[25,49]$. For the detection of monocytic cells, CD14 is a preferred IHC marker (Table 4). In case of very immature (CAE-negative) cells, CD14 and other monocytic markers (together with CD34) may help discriminate CMML from AML. Tryptase and CD117 are useful IHC markers to detect BM mast cells which are increased in almost all patients with MDS and may show spindle-shape appearance. If spindle-shaped mast cells are prominent and/or form compact clusters in the BM and/or express $\mathrm{CD} 25$, it is appropriate to perform mutation analysis of KIT (especially KIT D816V). In such cases, a coexisting mastocytosis (occult mastocytosis) is often detected (Table 4) $[16,25,50]$.

\section{KARYOTYPING IN MDS: CURRENT RECOMMENDATIONS AND STANDARDS}

Conventional karyotyping of BM cells should be performed in all patients with (suspected) MDS or pre-MDS. It is required by current recommendations to examine at least 20 metaphases [51]. When a clearcut result is obtained even 10-20 metaphases may be sufficient. Reporting of karyotypes should be performed using ISCN guidelines [52]. As per definition, a clone is defined by two or more metaphases showing the same gain or structural rearrangement (such as deletion, inversion or translocation) of chromosomal material or at least three metaphases showing loss of the same chromosome [52]. When no cell growth or no sufficient result can be obtained, FISH should be performed [16, 53, 54]. Combined application of conventional karyotyping and FISH increases the rate of detected chromosome abnormalities [54]. FISH analysis should cover at least the following regions: 5q31, cep7, 7q31, 20q, cep8, cepY and p53, being cognizant of the limitation of this method in not detecting all karyotypic abnormalities and for some probes not being MDS-defining (20q, cep8, cepY, p53). More recently it has been shown that FISH is a suitable alternative to serial $\mathrm{BM}$ investigations $[55,56]$. In fact, FISH analysis of enriched CD $34^{+}$blood cells is a sensitive approach that provides relevant cytogenetic information if $\mathrm{BM}$ is not available and may also be used for prognostication [55, 57]. If available, multi-color FISH can be applied, for example to decipher complex abnormalities or define unclear marker-chromosomes [58]. In general, almost all karyotype abnormalities in MDS are considered to represent somatic defects. In rare cases, however, there may be suspicion of a constitutional inborn defect. In these patients, T lymphocytes or non-hematopoietic cells, such as cultured fibroblasts should be examined. In up to $30 \%$ of patients with MDS, clonal evolution and the presence of one or more subclones is reported. A subclone is defined by detection of additional chromosomal defects (apart from the primary chromosome defect) in at least 2 cells (or 3 cells for monosomies) and absence of these additional defects in the other clonal cells. A complex karyotype is defined by at least 3 chromosome defects in one cell population (one clone) $[51,52]$. The recognition of clonal evolution in MDS patients over time is clinically relevant [58-60]. Therefore, karyotyping of BM or PB CD34 ${ }^{+}$ cells should be repeated during follow-up in patients with suspected progression. Although the definitive clinical impact of acquired additional chromosomal defects in MDS remains unknown, karyotypic evolution is in general associated with disease progression and a poor prognosis $[60,61]$. In addition, it is generally appreciated that cytogenetics at diagnosis remains a most important prognostic approach [62-64]. Therefore, karyotyping has been included in all relevant prognostic scoring systems. An overview of the most frequently detected cytogenetic abnormalities is shown in Supplementary Table S7.

\section{MUTATION PROFILES IN MDS AND PRE-MDS: CURRENT STANDARDS AND LIMITATIONS}

Cancer evolution is a stepwise process characterized by the acquisition of molecular lesions and other defects, resulting in clonal evolution and subclone formation, a related molecular diversification as well as clonal expansion [32, 65, 66]. The earliest steps of cancer evolution in MDS are expected to show just one or a few somatic mutations in driver genes that are recurrently mutated in myeloid malignancies, without histological abnormalities or cytopenia. Indeed, it has been reported that several disease-related mutations in critical target genes, such as DNMT3A or TET2, are detectable in a subset of healthy individuals (CHIP) or those with 'skewed' hematopoiesis without an overt MDS or AML [13-15]. These cases increase in prevalence with age and are defined as CHIP [15]. It can be expected that the numbers of diagnoses of CHIP will increase substantially as sequencing studies are applied broadly in daily practice. Some of these mutations may be associated with a substantial risk of transformation into MDS over time, whereas other mutations may be associated with a lower risk. However, only a few studies have addressed this issue so far [37]. The likelihood of evolution into MDS or AML in the follow-up may increase with the number of mutations detected and their allele burden.

In patients with overt MDS, numerous sequencing studies have been conducted in the recent past [67-76]. In these studies, it turned out that i) recurrent mutations are detectable in a majority of patients with MDS and ii) mutation profiling data can confirm the diagnosis of MDS [70-76]. Therefore, we are of the opinion that the documented presence of MDS-related mutations in BM or PB cells should be regarded as a new co-criterion for a provisional diagnosis of MDS. Mutation profiling in 
MDS is also of prognostic significance [73-76]. Because of the many recurrent mutations in MDS, next generation sequencing (NGS) strategies are generally required [7077]. Recently, comprehensive myeloid marker panels have been established and are used in clinical practice (Table 5) [70-77]. Some of these panels may be more specific for MDS and pre-MDS conditions whereas others may cover all myeloid neoplasms, including MDS. All in all, NGS profiling can be regarded as a new standard technique to define molecular aberration profiles in patients with suspected or established MDS. In some of these patients, the mutations detected may point to the presence of an overlap syndrome or a concomitant BM neoplasm. For example, the presence of $J A K 2 \mathrm{~V} 617 \mathrm{~F}$ will raise the suspicion of an MPN/MDS [78, 79], and detection of KIT D $816 \mathrm{~V}$ is usually associated with an underlying mastocytosis [23, 50]. Relevant mutations detected in MDS are shown in Table 5.

\section{FLOW CYTOMETRY IN MDS: STANDARDS AND LIMITATIONS}

A number of previous and more recent studies have shown that MFC can assist in the diagnosis and prognostication in MDS [80-87]. In cases with suspected MDS or pre-MDS conditions MFC may help in reaching the conclusion that $\mathrm{BM}$ cells are abnormal and/or immature, and that the cells examined express an aberrant immunophenotype suggesting the presence of a myeloid neoplasm. In addition, MFC can be employed to quantify $\left(\mathrm{CD} 34^{+}\right)$progenitor cells, erythroid progenitors, neutrophils, and/or monocytic precursor cells. Evaluation of immunophenotypic features of BM cells in patients with suspected MDS can yield three principal results, i.e. i) absence of MDS-related features, ii) inconclusive anomalies, and iii) anomalies highly consistent with a clonal myeloid neoplasm such as MDS [88]. In fact, although no marker-abnormality and no abnormal marker profile is MDS-specific, an accumulation of such changes may help in discriminating normal/ reactive $\mathrm{BM}$ from clonal conditions. The likelihood of a myeloid neoplasm (MDS) increases with the number of phenotypic aberrations detected [80-85]. However, the final diagnosis of MDS has to be based on additional (clinical and laboratory) criteria. A summary of recurrent immunophenotypes detected in myeloid cells in MDS is shown in Table 6. Apart from its value as diagnostic tool, immunophenotyping can also assist in the prognostication in MDS [86-91]. In addition, MFC may improve currently available prognostic scoring systems [92-95]. An obvious disadvantage of MFC is that no generally accepted consensus concerning the optimal standard-protocol and technique to apply exists. Current efforts and ongoing multi-center projects have the aim to standardize and harmonize methodologies and reagents, in order to increase the general impact and awareness of this important approach and to facilitate its use in daily practice [96]. Flow cytometry might also be useful for predicting responses to therapy in $\operatorname{MDS}[97,98]$.

\section{IMPACT OF PRE-MDS CONDITIONS ON DAILY PRACTICE AND HEALTH CARE STRATEGIES}

Sequencing studies of PB or cell-free plasmatic DNA are increasingly used to examine either germline predisposition to disease or for early diagnosis of cancer. Many such studies will identify CHIP, leading to an increasing number of referrals to hematology centers, and managing these referrals may become a challenge. In this regard, it will be important to implement the terminologies proposed herein (CHIP, CCUS) in daily practice. In addition, it is important to standardize the marker-panels and techniques applied to detect CHIP and CCUS. One important issue is the optimal germline control. Proposed germline controls are buccal swabs, hair follicles, nails, and cultured fibroblasts. Our faculty is of the opinion that reports providing information about genomic aberrations (or exome profiles) must include precise information regarding the sequencing technology and the analytic approach as well as information concerning the germline control if examined. The variant allele fraction should also be reported. However, other questions also remain. Should all affected individuals undergo a BM examination? Should CHIP and CCUS 'carriers' be informed that they are in a potential pre-phase of an overt blood cell disorder? Should management recommendations include avoidance of potential mutagenic events, such as smoking or radiation, in these cases? These questions remain open and can only be addressed appropriately in forthcoming observational studies. Finally, an important question is whether and how health care systems will be able to pay for the investigations, referrals, follow-up evaluation and management.

\section{SCORING SYSTEMS IN MDS: UPDATE AND RECOMMENDED STANDARDS}

Although more and more prognostic variables have been identified in the context of MDS and the updated WHO classification [9, 99] estimation of the clinical course and survival remains a clinical challenge. In order to address this challenge, a number of different scoring systems have been developed in the past. Until 2012, the IPSS served as a golden standard of prognostication [100-102]. However, in 2012, a revised IPSS, called IPSS-R has been published [103]. This new score improves prognostication in individual patients with MDS. The clinical value of the IPSS-R has been confirmed in numerous studies. Therefore, our faculty is of the opinion that the IPSS-R should be regarded as new 
golden standard of prognostication of MDS. However, even the IPSS-R has several limitations. For example, it remains unknown whether the IPSS-R is useful in patients receiving interventional therapy or targeted drugs. In addition, there are other independent risk factors that need to be considered, such as red blood cell transfusion dependence or genetic and somatic aberrations [71-76, 101]. Especially gene aberration profiles and MFC data may add in the predictive power of prognostic scoring systems. Therefore, molecular (genetic and somatic) aberrations and MFC-based aberration profiles should be validated and integrated in forthcoming refinements of the IPSS-R.

\section{CONCLUDING REMARKS AND FUTURE PERSPECTIVES}

The increasing number of diagnostic and prognostic parameters and assays and the advent of new therapeutic approaches in MDS are major challenges in daily practice. Moreover, more and more patients are referred in whom a potential pre-phase of MDS is diagnosed but definitive criteria of MDS are not fulfilled. Based on these developments, it is important to revisit and refine current diagnostic criteria and standards in MDS and to establish definitions and criteria for pre-MDS conditions. In the current article, we propose such definitions and criteria. In the emerging era of genome-medicine these criteria and the related terminologies may be of crucial importance and should assist in the evaluation of MDS and pre-MDS in daily practice.

\section{Abbreviations}

AML: acute myeloid leukemia; BM: Bone marrow; CAE: Chloroacetate esterase; CCUS: Clonal cytopenia of unknown significance; CHIP: Clonal hematopoiesis of indeterminate potential; FAB: French-AmericanBritish; FISH: Fluorescence in situ hybridization; ICUS: Idiopathic cytopenia of unknown significance; IDUS: Idiopathic dysplasia of unknown significance; IHC: Immunohistochemistry; IPSS: International prognostic scoring system; IPSS-R:Revised IPSS; MFC: multiparameter flow cytometry; MDS: Myelodysplastic syndrome(s); PB: Peripheral blood; RS: Ring sideroblasts; WHO: World Health Organization.

\section{Authors' contributions}

All co-authors contributed by establishing the concept, by participating in the pre-conference and postconference discussion-phases, by actively participating in the Working Conference, by formulating consensus statements, by writing parts of the manuscript, and by correcting and approving the final version of the document. Consensus statements were based on a $100 \%$ agreement (all faculty members agreed) and only those statements were included in this article.

\section{ACKNOWLEDGMENTS}

We like to thank Sabine Sonnleitner, Julia Neusiedler-Nicolas, Emir Hadzijusofovic, and all other involved group members (research group of Peter Valent) for their excellent support in the organization of the Working Conference.

\section{CONFLICTS OF INTEREST}

The authors declare that they have no conflict of interest in this study and paper.

\section{FUNDING}

This study was supported by the Austrian Science Fund (FWF) grant F4704-B20 and a Stem Cell Research Grant of the Medical University of Vienna.

\section{REFERENCES}

1. Hofmann WK, Koeffler HP. Myelodysplastic syndrome. Annu Rev Med. 2005; 56:1-16.

2. Nimer SD. Myelodysplastic syndromes. Blood. 2008; 111:4841-4851.

3. Bejar R, Levine R, Ebert BL. Unraveling the molecular pathophysiology of myelodysplastic syndromes. J Clin Oncol. 2011; 29:504-515.

4. Giagounidis A, Haase D. Morphology, cytogenetics and classification of MDS. Best Pract Res Clin Haematol. 2013; 26:337-353.

5. Bennett JM, Catovsky D, Daniel MT, Flandrin G, Galton DA, Gralnick HR, Sultan C. Proposals for the classification of the myelodysplastic syndromes. Br J Haematol. 1982; 51:189-199.

6. Bennett JM, Catovsky D, Daniel MT, Flandrin G, Galton DA, Gralnick HR, Sultan C, Cox C. The chronic myeloid leukaemias: guidelines for distinguishing chronic granulocytic, atypical chronic myeloid, and chronic myelomonocytic leukaemia. Proposals by the FrenchAmerican-British Cooperative Leukaemia Group. Br J Haematol. 1994; 87:746-754.

7. Brunning RD, Bennett JM, Flandrin G, Matutes E, Head D, Vardiman JW, Harris NL. Myelodysplastic Syndromes. in: World Health Organization Classification of Tumours. Pathology \& Genetics. Tumours of Haematopoietic and Lymphoid Tissues. Jaffe ES, Harris NL, Stein H, Vardiman JW (eds). IARC Press Lyon, 2001; 1:62-73.

8. Vardiman JW, Thiele J, Arber DA, Brunning RD, Borowitz MJ, Porwit A, Harris NL, Le Beau MM, Hellström- 
Lindberg E, Tefferi A, Bloomfield CD. The 2008 revision of the World Health Organization (WHO) classification of myeloid neoplasms and acute leukemia: rationale and important changes. Blood. 2009; 114:937-951.

9. Arber DA, Hasserjian RP. Reclassifying myelodysplastic syndromes: What's where in the new WHO and why. Hematology (Am Soc Hematol Educ Program). 2015; 294298.

10. Stauder R, Nösslinger $T$, Pfeilstöcker $M$, Sperr WR, Wimazal F, Krieger O, Valent P. Impact of age and comorbidity in myelodysplastic syndromes. J Natl Compr Canc Netw. 2008; 6:927-934.

11. Itzykson R, Kosmider O, Fenaux P. Somatic mutations and epigenetic abnormalities in myelodysplastic syndromes. Best Pract Res Clin Haematol. 2013; 26:355-364.

12. Zeidan AM, Gore SD, Padron E, Komrokji RS. Current state of prognostication and risk stratification in myelodysplastic syndromes. Curr Opin Hematol. 2015; 22:146-154.

13. Busque L, Patel JP, Figueroa ME, Vasanthakumar A, Provost S, Hamilou Z, Mollica L, Li J, Viale A, Heguy A, Hassimi M, Socci N, Bhatt PK, et al. Recurrent somatic TET2 mutations in normal elderly individuals with clonal hematopoiesis. Nat Genet. 2012; 44:1179-1181.

14. Genovese G, Kähler AK, Handsaker RE, Lindberg J, Rose SA, Bakhoum SF, Chambert K, Mick E, Neale BM, Fromer M, Purcell SM, Svantesson O, Landén M, et al. Clonal hematopoiesis and blood-cancer risk inferred from blood DNA sequence. N Engl J Med. 2014; 371:2477-2487.

15. Steensma DP, Bejar R, Jaiswal S, Lindsley RC, Sekeres MA, Hasserjian RP, Ebert BL. Clonal hematopoiesis of indeterminate potential and its distinction from myelodysplastic syndromes. Blood. 2015; 126:9-16.

16. Valent P, Horny HP, Bennett JM, Fonatsch C, Germing U, Greenberg P, Haferlach T, Haase D, Kolb HJ, Krieger O, Loken M, van de Loosdrecht A, Ogata K, et al. Definitions and standards in the diagnosis and treatment of the myelodysplastic syndromes: Consensus statements and report from a working conference. Leuk Res. 2007; $31: 727$ 736.

17. Valent P, Horny HP. Minimal diagnostic criteria for myelodysplastic syndromes and separation from ICUS and IDUS: update and open questions. Eur J Clin Invest. 2009; 39:548-553.

18. Schroeder T, Ruf L, Bernhardt A, Hildebrandt B, Aivado M, Aul C, Gattermann N, Haas R, Germing U. Distinguishing myelodysplastic syndromes (MDS) from idiopathic cytopenia of undetermined significance (ICUS): HUMARA unravels clonality in a subgroup of patients. Ann Oncol. 2010; 21:2267-2271.

19. Valent P, Bain BJ, Bennett JM, Wimazal F, Sperr WR, Mufti G, Horny HP. Idiopathic cytopenia of undetermined significance (ICUS) and idiopathic dysplasia of uncertain significance (IDUS), and their distinction from low risk MDS. Leuk Res. 2012; 36:1-5.
20. Steensma DP. Dysplasia has a differential diagnosis: distinguishing genuine myelodysplastic syndromes (MDS) from mimics, imitators, copycats and impostors. Curr Hematol Malig Rep. 2012; 7:310-320.

21. Valent P. Low blood counts: immune mediated, idiopathic, or myelodysplasia. Hematology Am Soc Hematol Educ Program. 2012; 2012:485-491.

22. Greenberg PL, Tuechler H, Schanz J, Sanz G, GarciaManero G, Solé F, Bennett JM, Bowen D, Fenaux P, Dreyfus F, Kantarjian H, Kuendgen A, Levis A, et al. Cytopenia levels for aiding establishment of the diagnosis of myelodysplastic syndromes. Blood. 2016; 128:20962097.

23. Horny HP, Sotlar K, Valent P. Diagnostic value of histology and immunohistochemistry in myelodysplastic syndromes. Leuk Res. 2007; 31:1609-1616.

24. Orazi A, Czader MB. Myelodysplastic syndromes. Am J Clin Pathol. 2009; 132:290-305.

25. Valent P, Orazi A, Büsche G, Schmitt-Gräff A, George TI, Sotlar K, Streubel B, Beham-Schmid C, CernyReiterer S, Krieger O, van de Loosdrecht A, Kern W, Ogata K, et al. Standards and impact of hematopathology in myelodysplastic syndromes (MDS). Oncotarget. 2010; 1:483-496. doi: 10.18632/oncotarget.101104.

26. Auner HW, Klintschar M, Crevenna R, Beham-Schmid C, Hoefler G, Mitterbauer G, Linkesch W, Sill H. Two case studies of chronic idiopathic neutropenia preceding acute myeloid leukaemia. Br J Haematol. 1999; 105:431-433.

27. Wimazal F, Fonatsch C, Thalhammer R, Schwarzinger I, Müllauer L, Sperr WR, Bennett JM, Valent P. Idiopathic cytopenia of undetermined significance (ICUS) versus low risk MDS: the diagnostic interface. Leuk Res. 2007; 31:1461-1468.

28. Malcovati L, Cazzola M. The shadowlands of MDS: idiopathic cytopenias of undetermined significance (ICUS) and clonal hematopoiesis of indeterminate potential (CHIP). Hematology Am Soc Hematol Educ Program. 2015; 2015:299-307.

29. Petrova-Drus K, Hasserjian R, Pozdnyakova O, Dal Cin P, Mathew S, Margolskee E, Orazi A, Geyer JT. Clinicopathologic evaluation of cytopenic patients with isolated trisomy 8: a detailed comparison between idiopathic cytopenia of unknown significance and lowgrade myelodysplastic syndrome. Leuk Lymphoma. 2016; 7:1-9.

30. Valent P, Jäger E, Mitterbauer-Hohendanner G, Müllauer L, Schwarzinger I, Sperr WR, Thalhammer R, Wimazal F. Idiopathic bone marrow dysplasia of unknown significance (IDUS): definition, pathogenesis, follow up, and prognosis. Am J Cancer Res. 2011; 1:531-541.

31. Hahn WC, Weinberg RA. Modelling the molecular circuitry of cancer. Nat Rev Cancer. 2002; 2:331-241.

32. Valent P, Bonnet D, De Maria R, Lapidot T, Copland M, Melo JV, Chomienne C, Ishikawa F, Schuringa JJ, Stassi 
G, Huntly B, Herrmann H, Soulier J, et al. Cancer stem cell definitions and terminology: the devil is in the details. Nat Rev Cancer. 2012; 12:767-775.

33. Jaiswal S, Fontanillas P, Flannick J, Manning A, Grauman PV, Mar BG, Lindsley RC, Mermel CH, Burtt N, Chavez A, Higgins JM, Moltchanov V, Kuo FC, et al. Age-related clonal hematopoiesis associated with adverse outcomes. N Engl J Med. 2014; 371:2488-2498.

34. Gillis NK, Ball M, Zhang Q, Ma Z, Zhao Y, Yoder SJ, Balasis ME, Mesa TE, Sallman DA, Lancet JE, Komrokji RS, List AF, McLeod HL, et al. Clonal haemopoiesis and therapy-related myeloid malignancies in elderly patients: a proof-of-concept, case-control study. Lancet Oncol. 2017; 18:112-121.

35. Takahashi K, Wang F, Kantarjian H, Doss D, Khanna K, Thompson E, Zhao L, Patel K, Neelapu S, Gumbs C, Bueso-Ramos C, DiNardo CD, Colla S, et al. Preleukaemic clonal haemopoiesis and risk of therapy-related myeloid neoplasms: a case-control study. Lancet Oncol. 2017; 18:100-111.

36. Gibson CJ, Lindsley RC, Tchekmedyian V, Mar BG, Shi J, Jaiswal S, Bosworth A, Francisco L, He J, Bansal A, Morgan EA, Lacasce AS, Freedman AS, et al. Clonal Hematopoiesis Associated With Adverse Outcomes After Autologous Stem-Cell Transplantation for Lymphoma. J Clin Oncol. 2017; 35:1598-1605.

37. Steensma DP, Abedi M, Bejar R, Cogle CR, Foucar K, Garcia-Manero G, George TI, Grinblatt D, Komrokji R, Ma X, Maciejewski J, Pollyea DA, Savona MR, et al. Connect MDS/AML: design of the myelodysplastic syndromes and acute myeloid leukemia disease registry, a prospective observational cohort study. BMC Cancer. 2016; 16:652.

38. Bennett JM, Kouides PA, Forman SJ. The myelodysplastic syndromes: morphology, risk assessment, and clinical management (2002). Int J Hematol. 2002; 76:228-238.

39. Mufti GJ, Bennett JM, Goasguen J, Bain BJ, Baumann I, Brunning R, Cazzola M, Fenaux P, Germing U, Hellström-Lindberg E, Jinnai I, Manabe A, Matsuda A, et al. Diagnosis and classification of myelodysplastic syndrome: International Working Group on Morphology of myelodysplastic syndrome (IWGM-MDS) consensus proposals for the definition and enumeration of myeloblasts and ring sideroblasts. Haematologica. 2008; 93:1712-1717.

40. Della Porta MG, Travaglino E, Boveri E, Ponzoni M, Malcovati L, Papaemmanuil E, Rigolin GM, Pascutto C, Croci G, Gianelli U, Milani R, Ambaglio I, Elena C, et al. Minimal morphological criteria for defining bone marrow dysplasia: a basis for clinical implementation of WHO classification of myelodysplastic syndromes. Leukemia. 2015; 29:66-75

41. Arber DA, Orazi A, Hasserjian R, Thiele J, Borowitz MJ, Le Beau MM, Bloomfield CD, Cazzola M, Vardiman JW. The 2016 revision to the World Health Organization classification of myeloid neoplasms and acute leukemia. Blood. 2016; 127:2391-2405.
42. Germing U, Strupp C, Giagounidis A, Haas R, Gattermann N, Starke C, Aul C. Evaluation of dysplasia through detailed cytomorphology in 3156 patients from the Düsseldorf Registry on myelodysplastic syndromes. Leuk Res. 2012; 36:727-734.

43. Bennett JM, Tuechler H, Aul C, Strupp C, Germing U. Dysplastic erythroid precursors in the myelodysplastic syndromes and the acute myeloid leukemias: Is there biologic significance? (How should blasts be counted?). Leuk Res. 2016; 47:63-69.

44. Tuzuner N, Bennett JM. Reference standards for bone marrow cellularity. Leuk Res. 1994; 18:645-647.

45. Tuzuner N, Cox C, Rowe JM, Bennett JM. Bone marrow cellularity in myeloid stem cell disorders: impact of age correction. Leuk Res. 1994; 18:559-564.

46. Schemenau J, Baldus S, Anlauf M, Reinecke P, Braunstein S, Blum S, Nachtkamp K, Neukirchen J, Strup C, Aul C, Haas R, Gattermann N, Germing U. Cellularity, characteristics of hematopoietic parameters and prognosis in myelodysplastic syndromes. Eur J Haematol. 2015; 95:181-189.

47. Horny HP, Wehrmann M, Schlicker HU, Eichstaedt A, Clemens MR, Kaiserling E. QBEND10 for the diagnosis of myelodysplastic syndromes in routinely processed bone marrow biopsy specimens. J Clin Pathol. 1995; 48:291-294.

48. Orazi A, Albitar M, Heerema NA, Haskins S, Neiman RS. Hypoplastic myelodysplastic syndromes can be distinguished from acquired aplastic anemia by CD34 and PCNA immunostaining of bone marrow biopsy specimens. Am J Clin Pathol. 1997; 107:268-274.

49. Thiele J, Quitmann H, Wagner S, Fischer R. Dysmegakaryopoiesis in myelodysplastic syndromes (MDS): an immunomorphometric study of bone marrow trephine biopsy specimens. J Clin Pathol. 1991; 44:300-305.

50. Horny HP, Sotlar K, Valent P. Differential diagnoses of systemic mastocytosis in routinely processed bone marrow biopsy specimens: a review. Pathobiology. 2010; 77:169180.

51. Steidl C, Steffens R, Gassmann W, Hildebrandt B, Hilgers $\mathrm{R}$, Germing U, Trumper L, Haase D. Adequate cytogenetic examination in myelodysplastic syndromes: analysis of 529 patients. Leuk Res. 2005; 29:987-993.

52. ISCN: an international system for human cytogenetic nomenclature (2016). Editors: Jean McGowan-Jordan, Annet Simons, Michael Schmid. Karger Basel, New York, 2016.

53. Romeo M, Chauffaille Mde L, Silva MR, Bahia DM, Kerbauy J. Comparison of cytogenetics with FISH in 40 myelodysplastic syndrome patients. Leuk Res. 2002; 26:993-996.

54. Bernasconi P, Cavigliano PM, Boni M, Calatroni S, Klersy C, Giardini I, Rocca B, Crosetto N, Caresana M, Lazzarino $\mathrm{M}$, Bernasconi C. Is FISH a relevant prognostic tool in myelodysplastic syndromes with a normal chromosome 
pattern on conventional cytogenetics? A study on 57 patients. Leukemia. 2003; 17:2107-2112.

55. Braulke F, Jung K, Schanz J, Götze K, Müller-Thomas C, Platzbecker U, Germing U, Brümmendorf TH, Bug G, Ottmann O, Giagounidis AA, Stadler M, Hofmann WK, et al. Molecular cytogenetic monitoring from CD34+ peripheral blood cells in myelodysplastic syndromes: First results from a prospective multicenter German diagnostic study. Leuk Res. 2013; 37:900-906.

56. Cherry AM, Slovak ML, Campbell LJ, Chun K, Eclache V, Haase D, Haferlach C, Hildebrandt B, Iqbal AM, Jhanwar SC, Ohyashiki K, Sole F, Vandenberghe P, et al. Will a peripheral blood (PB) sample yield the same diagnostic and prognostic cytogenetic data as the concomitant bone marrow (BM) in myelodysplasia? Leuk Res. 2012; 36:832840.

57. Braulke F, Platzbecker U, Müller-Thomas C, Götze K, Germing U, Brümmendorf TH, Nolte F, Hofmann WK, Giagounidis AA, Lübbert M, Greenberg PL, Bennett JM, Solé F, et al. Validation of cytogenetic risk groups according to International Prognostic Scoring Systems by peripheral blood CD34+FISH: results from a German diagnostic study in comparison with an international control group. Haematologica. 2015; 100:205-213.

58. Babicka L, Ransdorfova S, Brezinova J, Zemanova Z, Sindelarova L, Siskova M, Maaloufova J, Cermak $\mathrm{J}$, Michalova K. Analysis of complex chromosomal rearrangements in adult patients with MDS and AML by multicolor FISH. Leuk Res. 2007; 31:39-47.

59. Tricot G, Boogaerts MA, De Wolf-Peeters C, Van den Berghe H, Verwilghen RL. The myelodysplastic syndromes: different evolution patterns based on sequential morphological and cytogenetic investigations. $\mathrm{Br} \mathrm{J}$ Haematol. 1985; 59:659-670.

60. Horiike S, Taniwaki M, Misawa S, Abe T. Chromosome abnormalities and karyotypic evolution in 83 patients with myelodysplastic syndrome and predictive value for prognosis. Cancer. 1988; 62:1129-1138.

61. Jabbour E, Takahashi K, Wang X, Cornelison AM, Abruzzo L, Kadia T, Borthakur G, Estrov Z, O'Brien S, Mallo M, Wierda W, Pierce S, Wei Y, et al. Acquisition of cytogenetic abnormalities in patients with IPSS defined lower-risk myelodysplastic syndrome is associated with poor prognosis and transformation to acute myelogenous leukemia. Am J Hematol. 2013; 88:831-837.

62. Haase D. Cytogenetic features in myelodysplastic syndromes. Ann Hematol. 2008; 87:515-526.

63. Schanz J, Steidl C, Fonatsch C, Pfeilstöcker M, Nösslinger T, Tuechler H, Valent P, Hildebrandt B, Giagounidis A, Aul C, Lübbert M, Stauder R, Krieger O, et al. Coalesced multicentric analysis of 2,351 patients with myelodysplastic syndromes indicates an underestimation of poor-risk cytogenetics of myelodysplastic syndromes in the international prognostic scoring system. J Clin Oncol. 2011; 29:1963-1970.
64. Schanz J, Tüchler H, Solé F, Mallo M, Luño E, Cervera J, Granada I, Hildebrandt B, Slovak ML, Ohyashiki K, Steidl C, Fonatsch C, Pfeilstöcker M, et al. New comprehensive cytogenetic scoring system for primary myelodysplastic syndromes (MDS) and oligoblastic acute myeloid leukemia after MDS derived from an international database merge. J Clin Oncol. 2012; 30:820-829.

65. Greaves M, Maley CC. Clonal evolution in cancer. Nature. 2012; 481:306-313.

66. Yates LR, Campbell PJ. Evolution of the cancer genome. Nat Rev Genet. 2012; 13:795-806.

67. Hofmann WK, de Vos S, Komor M, Hoelzer D, Wachsman W, Koeffler HP. Characterization of gene expression of CD34+ cells from normal and myelodysplastic bone marrow. Blood. 2002; 100:3553-3560.

68. Ueda M, Ota J, Yamashita Y, Choi YL, Ohki R, Wada T, Koinuma K, Kano Y, Ozawa K, Mano H. DNA microarray analysis of stage progression mechanism in myelodysplastic syndrome. Br J Haematol. 2003; 123:288-296.

69. Pellagatti A, Esoof N, Watkins F, Langford CF, Vetrie D, Campbell LJ, Fidler C, Cavenagh JD, Eagleton H, Gordon P, Woodcock B, Pushkaran B, Kwan M, et al. Gene expression profiling in the myelodysplastic syndromes using cDNA microarray technology. Br J Haematol. 2004; 125:576-583.

70. Chen G, Zeng W, Miyazato A, Billings E, Maciejewski JP, Kajigaya S, Sloand EM, Young NS. Distinctive gene expression profiles of CD34 cells from patients with myelodysplastic syndrome characterized by specific chromosomal abnormalities. Blood. 2004; 104:4210-4218.

71. Bejar R, Stevenson K, Abdel-Wahab O, Galili N, Nilsson B, Garcia-Manero G, Kantarjian H, Raza A, Levine RL, Neuberg D, Ebert BL. Clinical effect of point mutations in myelodysplastic syndromes. N Engl J Med. 2011; 364:2496-2506.

72. Papaemmanuil E, Gerstung M, Malcovati L, Tauro S, Gundem G, Van Loo P, Yoon CJ, Ellis P, Wedge DC, Pellagatti A, Shlien A, Groves MJ, Forbes SA, et al. Clinical and biological implications of driver mutations in myelodysplastic syndromes. Blood. 2013; 122:3616-3627.

73. Haferlach T, Nagata Y, Grossmann V, Okuno Y, Bacher U, Nagae G, Schnittger S, Sanada M, Kon A, Alpermann T, Yoshida K, Roller A, Nadarajah N, et al. Landscape of genetic lesions in 944 patients with myelodysplastic syndromes. Leukemia. 2014; 28:241-247.

74. Duncavage EJ, Tandon B. The utility of next-generation sequencing in diagnosis and monitoring of acute myeloid leukemia and myelodysplastic syndromes. Int J Lab Hematol. 2015; 37:115-121.

75. Bacher U, Kohlmann A, Haferlach T. Mutational profiling in patients with MDS: ready for every-day use in the clinic? Best Pract Res Clin Haematol. 2015; 28:32-42.

76. Reinig E, Yang F, Traer E, Arora R, Brown S, Rattray R, Braziel R, Fan G, Press R, Dunlap J. Targeted next- 
generation sequencing in myelodysplastic syndrome and chronic myelomonocytic leukemia aids diagnosis in challenging cases and identifies frequent spliceosome mutations in transformed acute myeloid leukemia. Am J Clin Pathol. 2016; 145:497-506.

77. Albitar F, Ma W, Diep K, De Dios I, Agersborg S, Thangavelu M, Brodie S, Albitar M. Deep Sequencing of Cell-Free Peripheral Blood DNA as a Reliable Method for Confirming the Diagnosis of Myelodysplastic Syndrome. Genet Test Mol Biomarkers. 2016; 20:341-345.

78. Ohyashiki K, Aota Y, Akahane D, Gotoh A, Miyazawa K, Kimura Y, Ohyashiki JH. The JAK2 V617F tyrosine kinase mutation in myelodysplastic syndromes (MDS) developing myelofibrosis indicates the myeloproliferative nature in a subset of MDS patients. Leukemia. 2005; 19:2359-2360.

79. Ingram $\mathrm{W}$, Lea $\mathrm{NC}$, Cervera J, Germing U, Fenaux P, Cassinat B, Kiladjian JJ, Varkonyi J, Antunovic P, Westwood NB, Arno MJ, Mohamedali A, Gaken J, et al. The JAK2 V617F mutation identifies a subgroup of MDS patients with isolated deletion $5 \mathrm{q}$ and a proliferative bone marrow. Leukemia. 2006; 20:1319-1321.

80. Ogata K, Nakamura K, Yokose N, Tamura H, Tachibana M, Taniguchi O, Iwakiri R, Hayashi T, Sakamaki H, Murai Y, Tohyama K, Tomoyasu S, Nonaka Y, et al. Clinical significance of phenotypic features of blasts in patients with myelodysplastic syndrome. Blood. 2002; 100:3887-3896.

81. Malcovati L, Della Porta MG, Lunghi M, Pascutto C, Vanelli L, Travaglino E, Maffioli M, Bernasconi P, Lazzarino M, Invernizzi R, Cazzola M. Flow cytometry evaluation of erythroid and myeloid dysplasia in patients with myelodysplastic syndrome. Leukemia. 2005; 19:776783.

82. Westers TM, Cremers EM, Oelschlaegel U, Johansson U, Bettelheim P, Matarraz S, Orfao A, Moshaver B, Brodersen LE, Loken MR, Wells DA, Subirá D, Cullen M, et al. Immunophenotypic analysis of erythroid dysplasia in myelodysplastic syndromes. A report from the IMDSFlow working group. Haematologica. 2017; 102:308-319.

83. Ogata K, Kishikawa Y, Satoh C, Tamura H, Dan K, Hayashi A. Diagnostic application of flow cytometric characteristics of CD34+ cells in low-grade myelodysplastic syndromes. Blood. 2006; 108:1037-1044.

84. Eidenschink Brodersen L, Menssen AJ, Wangen JR, Stephenson CF, de Baca ME, Zehentner BK, Wells DA, Loken MR. Assessment of erythroid dysplasia by "difference from normal" in routine clinical flow cytometry workup. Cytometry B Clin Cytom. 2015; 88:125-135.

85. Cremers EM, Westers TM, Alhan C, Cali C, Wondergem MJ, Poddighe PJ, Ossenkoppele GJ, van de Loosdrecht AA. Multiparameter flow cytometry is instrumental to distinguish myelodysplastic syndromes from non-neoplastic cytopenias. Eur J Cancer. 2016; 54:49-56.

86. Wells DA, Benesch M, Loken MR, Vallejo C, Myerson D, Leisenring WM, Deeg HJ. Myeloid and monocytic dyspoiesis as determined by flow cytometric scoring in myelodysplastic syndrome correlates with the IPSS and with outcome after hematopoietic stem cell transplantation. Blood. 2003; 102:394-403.

87. Benesch M, Deeg HJ, Wells D, Loken M. Flow cytometry for diagnosis and assessment of prognosis in patients with myelodysplastic syndromes. Hematology. 2004; 9:171-177.

88. Porwit A, van de Loosdrecht AA, Bettelheim P, Brodersen LE, Burbury K, Cremers E, Della Porta MG, Ireland R, Johansson U, Matarraz S, Ogata K, Orfao A, Preijers F, et al. Revisiting guidelines for integration of flow cytometry results in the WHO classification of myelodysplastic syndromes-proposal from the International/European LeukemiaNet Working Group for Flow Cytometry in MDS. Leukemia. 2014; 28:1793-1798.

89. Arroyo JL, Fernandez ME, Hernandez JM, Orfao A, San Miguel JF, del Canizo MC. Impact of immunophenotype on prognosis of patients with myelodysplastic syndromes. Its value in patients without karyotypic abnormalities. Hematol J. 2004; 5:227-233.

90. Cremers EM, Westers TM, Alhan C, Cali C, VisserWisselaar HA, Chitu DA, van der Velden VH, Te Marvelde JG, Klein SK, Muus P, Vellenga E, de Greef GE, Legdeur $\mathrm{MC}$, et al. Implementation of erythroid lineage analysis by flow cytometry in diagnostic models for myelodysplastic syndromes. Haematologica. 2017; 102:320-326.

91. Kern W, Bacher U, Haferlach C, Alpermann T, Schnittger $\mathrm{S}$, Haferlach T. Multiparameter flow cytometry provides independent prognostic information in patients with suspected myelodysplastic syndromes: A study on 804 patients. Cytometry B Clin Cytom. 2015; 88:154-164.

92. Alhan C, Westers TM, Cremers EM, Cali C, Witte BI, Ossenkoppele GJ, van de Loosdrecht AA. High flow cytometric scores identify adverse prognostic subgroups within the revised international prognostic scoring system for myelodysplastic syndromes. Br J Haematol. 2014; 167:100-109.

93. Alhan C, Westers TM, Cremers EM, Cali C, Witte BI, Ossenkoppele GJ, van de Loosdrecht AA. The myelodysplastic syndromes flow cytometric score: a threeparameter prognostic flow cytometric scoring system. Leukemia. 2016; 30:658-665.

94. Kahn JD, Chamuleau ME, Westers TM, Van de Ven PM, van Dreunen L, van Spronsen M, Ossenkoppele GJ, van de Loosdrecht AA. Regulatory $\mathrm{T}$ cells and progenitor $\mathrm{B}$ cells are independent prognostic predictors in lower risk myelodysplastic syndromes. Haematologica. 2015; 100:e220-e222.

95. Oelschlaegel U, Westers TM, Mohr B, Kramer M, Parmentier S, Sockel K, Thiede C, Bornhäuser M, Ehninger G, van de Loosdrecht AA, Platzbecker U. Myelodysplastic syndromes with a deletion $5 \mathrm{q}$ display a characteristic immunophenotypic profile suitable for diagnostics and response monitoring. Haematologica. 2015; 100:e93-e96.

96. Westers TM, Ireland R, Kern W, Alhan C, Balleisen JS, Bettelheim P, Burbury K, Cullen M, Cutler JA, Della Porta 
MG, Dräger AM, Feuillard J, Font P, et al. Standardization of flow cytometry in myelodysplastic syndromes: a report from an international consortium and the European LeukemiaNet Working Group. Leukemia. 2012; 26:17301741.

97. Alhan C, Westers TM, van der Helm LH, Eeltink C, Huls G, Witte BI, Buchi F, Santini V, Ossenkoppele GJ, van de Loosdrecht AA. Absence of aberrant myeloid progenitors by flow cytometry is associated with favorable response to azacitidine in higher risk myelodysplastic syndromes. Cytometry B Clin Cytom. 2014; 86:207-215.

98. Westers TM, Alhan C, Chamuleau ME, van der Vorst MJ, Eeltink C, Ossenkoppele GJ, van de Loosdrecht AA. Aberrant immunophenotype of blasts in myelodysplastic syndromes is a clinically relevant biomarker in predicting response to growth factor treatment. Blood. 2010; 115:1779-1784.

99. Strupp C, Nachtkamp K, Hildebrandt B, Giagounidis A, Haas R, Gattermann N, Bennett JM, Aul C, Germing U. New proposals of the WHO working group (2016) for the diagnosis of myelodysplastic syndromes (MDS): Characteristics of refined MDS types. Leuk Res. 2017; 57:78-84.
100. Greenberg P, Cox C, LeBeau MM, Fenaux P, Morel P, Sanz G, Sanz M, Vallespi T, Hamblin T, Oscier D, Ohyashiki K, Toyama K, Aul C, et al. J.International scoring system for evaluating prognosis in myelodysplastic syndromes. Blood. 1997; 89:2079-2088.

101. Malcovati L, Della Porta MG, Pascutto C, Invernizzi R, Boni M, Travaglino E, Passamonti F, Arcaini L, Maffioli M, Bernasconi P, Lazzarino M, Cazzola M. Prognostic factors and life expectancy in myelodysplastic syndromes classified according to WHO criteria: a basis for clinical decision making. J Clin Oncol. 2005; 23:7594-7603.

102. Bennett JM, Komrokji RS. The myelodysplastic syndromes: diagnosis, molecular biology and risk assessment. Hematology. 2005; 10:258-269.

103. Greenberg PL, Tuechler H, Schanz J, Sanz G, GarciaManero G, Solé F, Bennett JM, Bowen D, Fenaux P, Dreyfus F, Kantarjian H, Kuendgen A, Levis A, et al. Revised international prognostic scoring system for myelodysplastic syndromes. Blood. 2012; 120:2454-2465. 